\title{
EPITAFIOS DE NOVELA: \\ LA POESÍA FUNERAL DE CERVANTES \\ EN LA GALATEA, LOS QUIJOTES Y EL PERSILES
}

\author{
Adrián J. Sáez \\ UNIVERSITÀ CA’ FOSCARI DI VENEZIA
}

La muerte en Cervantes es un asunto muy vivo, aunque a veces pueda parecer más bien algo condenado a pinchar en hueso por el interés que despierta la controvertida cuestión de los restos del ingenio. De todas las formas que puede adoptar en la obra cervantina (batallas, duelos, suicidios...), brilla una galería de poemas dedicados especialmente a la muerte, que se relacionan con una cierta tradición poética y la vigencia de los ars bene moriendi en la época.

Verdaderamente, la poesía funeral cervantina se puede escindir en dos grupos: 1) los poemas fúnebres sueltos dedicados a diversas circunstancias luctuosas (núms. 1-5, 25-26, 28 y alguno más atribuido) (Sáez, en prensa), que se sitúan especialmente en la juventud de Cervantes como ejercicios escolares y estrategia cortesana; y 2) las poesías funerales novelescas que se hallan dentro de relatos en prosa con una función íntimamente relacionada con la ficción ${ }^{1}$. Aunque ambas series son hermanas, conviene examinarlas por separado, por lo que en esta ocasión me centro en las poesías fúnebres de La Galatea (1585), los dos Quijotes (1605 y 1615) y Los trabajos de Persiles y Sigismunda (1617), para lo que antes de nada conviene decir algo sobre este modelo poético.

\section{EPITAFIOS NOVELESCOS: UNA POESÍA DE MUERTE}

En dos palabras, la poesía funeral se dedica a la celebración de una muerte para consolación, lamento y/o lisonja, por lo que suele poseer un marcado carácter circunstancial que favorece ciertos rasgos compositivos, ya que esta suerte de poemas podía presentarse en los monumentos funerarios oportunos. A partir de un origen clásico que se remonta muy atrás, la recuperación humanista del Cinquecento revitaliza un esquema muy oportuno para la enseñanza por el trámite de la imitatio (Ponce Cárdenas 2014).

A más de otras cuestiones de interés (formas métricas, adición de otros elementos, etc.; Llamas Martínez 2016), es capital tener en cuenta el deslinde entre la variedad panegírica y el contrapunto burlesco, junto a la preferencia por el epitafio, modalidad que a veces parece ocupar la escena en solitario. En esencia, el patrón epitáfico se caracteriza por 1) la concisión y concentración expresivas, 2) los alardes de agudeza desde las variaciones cancioneriles hasta los chascarrillos ingeniosos, 3) la estructura bipartita con una declaración de las circunstancias de la muerte con más o menos detalles (narratio) y una reflexión ingeniosa a modo de remate final (acumen, con frecuentes guiños al receptor a partir del recuerdo de la lápida), 4) la perfección técnica y la cohesión, 5) la naturaleza circunstancial y el origen en academias, justas y círculos similares, 6) la exhibición del buen quehacer poético junto a la búsqueda del deleite, la admiratio y el movere, que puede valer para el elogio o la vituperatio, 7) el uso de una amplia cantera de recursos retóricos y 8) la variedad métrica (con predilección sonetil) (López Poza 2006).

En la amplia nómina de poemas novelescos cervantinos, se hallan doce poesías funerales más un ejemplo en prosa, que van de principio a fin de la carrera cervantina:

\footnotetext{
${ }^{1}$ Con esta consideración, matizo el corpus manejado por Montero Reguera (2011 y 2012): ver infra.
} 
1. La "Elegía por Meliso" de La Galatea (VI), primero de los poemas fúnebres novelescos que se relaciona directamente con los intereses cortesanos cervantinos.

2. La "Canción desesperada" de Grisóstomo (Quijote, I, 14), que deriva de un esquema italiano (Alonso 2008) y dentro de la acción funciona como una verdadera nota suicida (Sáez 2015: 213), a la que sigue después el epitafio de Ambrosio (I, 14).

3. La pareja de sonetos a la pérdida de La Goleta (I, 40), que pertenece a la familia del epitafio heroico (Ponce Cárdenas 2016: 143-174).

4. La serie de seis poesías lapidarias (tres epitafios y tres elogios) de los académicos de Argamasilla (I, 52), que juguetea burlescamente con el modelo de la poesía funeral.

5. El epitafio de Sansón Carrasco a Don Quijote (II, 74) en el final de la novela.

6. La inscripción mortuoria de Manuel de Sosa Coutiño en el Persiles (III, 1), que viene a ser la versión en prosa que cierra todas las calas precedentes.

Hay para todos los gustos, pero tanto las Novelas ejemplares como el teatro carecen de poesías funerales. Para entender de antemano esta distribución, se debe tener en cuenta que desde el amplio cancionero de La Galatea hay una progresiva reducción de las poesías en las novelas cervantinas (Díez Fernández 1996: 194), que tal vez se pueda relacionar con las distintas elecciones genéricas y el gran envite poético lanzado con el Viaje del Parnaso.

\section{“ET IN ARCADIA EGO”: UNA ELEGÍA CORTESANA}

A más de otras cosas, La Galatea de Cervantes se distingue por la fuerza de la violencia y la presentación de diversas formas de muertes en una desviación del universo de paz de la novela pastoril. Entre este reguero, brilla la "Elegía por Meliso", un poema funeral dedicado a un ilustre pastor que nunca aparece en el relato y que, en el juego de claves ocultas de la poética pastoril, representa al poeta y diplomático Diego Hurtado de Mendoza. Y lo hace con toda la intención, porque el encomio es un ejercicio de canonización de un ejemplo de perfecto cortesano y de la poética rinascimentale tan del gusto de Cervantes, al tiempo que constituye igualmente una atrevida muestra de cercanía al partido "papista" al que el poeta trataba de arrimarse en su día 2 . Por ello, guarda un cierto parentesco con la "Elegía a don Diego de Espinosa" (núm. 5), otro poema funeral con intereses cortesanos.

El lance, dividido en dos partes (libros V y VI), se desarrolla a las órdenes de Telesio, "un antiguo sacerdote" de identidad discutida que en la novela suele convocar a los pastores a golpe de bocina para "hacerles algún provechoso razonamiento, o decirles la muerte de algún pastor de aquellos contornos, o para traerles a la memoria el día de alguna solemne fiesta o el de algunas tristes obsequias" $(\mathrm{V}, 337)^{3}$.

Trágica es la cosa en esta ocasión, pues Telesio invita a todos a la celebración de las honras fúnebres de Meliso:

${ }^{2}$ Ruiz Pérez (2010: 417) indica que se trata de “un auténtico proceso canonizador" que presenta alabanzas y composiciones laudatorias similares a las guirnaldas poéticas de los entornos reales, como los textos recogidos en las Anotaciones de Herrera en loor de Garcilaso. A su vez, Marín Cepeda (2015: 401-404) recuerda con razón que la evocación de Hurtado de Mendoza en 1585, durante el reinado de Felipe II, "era mencionar la soga en casa del ahorcado" porque había caído en desgracia en el marco del controvertido episodio del príncipe don Carlos y, asimismo, anota la dificultad de determinar las afinidades políticas del personaje, que oscila entre varias facciones políticas.

${ }^{3}$ Se le ha relacionado con el sacerdote Bernardino Telesio (Márquez Villanueva 2005, entre otros) y con el humanista Ambrosio de Morales (Gil-Osle 2013: 45-58). Se cita siempre por las ediciones consignadas en la bibliografía, con ocasionales retoques de puntuación. 
quiéroos traer a la memoria la que debéis tener perpetuamente del valor y fama del famoso y aventajado pastor Meliso, cuyas dolorosas obsequias se renuevan e irán renovando de año en año tal día como mañana, en tanto que en nuestras riberas hubiere pastores y en nuestras almas no faltare el conocimiento de lo que se debe a la bondad y valor de Meliso. A lo menos, de mí os sé decir que, en tanto que la vida me durare, no dejaré de acordaros a su tiempo la obligación en que os tiene puestos la habilidad, cortesía y virtud del sin par Meliso (V, 338).

Con este parlamento, que ya principia el elogio del personaje, Telesio convoca a los pastores a la celebración de las exequias en el Valle de los Cipreses, donde está "el sepulcro de las honradas cenizas de Meliso, para que allí, con tristes cantos y piadosos sacrificios, procuremos aligerar la pena, si alguna padece, a aquella venturosa alma, que en tanta soledad nos ha dejado" (v, 338).

En la reanudación del lance tras un pequeño paréntesis que sirve para insertar otra poesía (las coplas de arrepentimiento de Lenio) y permite avanzar la acción de coladillo, se pone en marcha la comitiva pastoril y se suceden los signos de luto tanto en forma de acordes musicales (el "lastimero son" de la "bocina" de Telesio) como de hábitos solemnes ("que bien mostraban que para triste y lamentable negocio habían sido juntados", VI, 343), en alianza con otros signos de carácter ritual (separación de sexos, VI, 343; "un maravilloso silencio", VI, 344; las guirnaldas de ciprés, VI, 348; "el sacro fuego" y "las piadosas plegarias", vI, 349, etc.), todo en un paraíso terrestre a orillas del Tajo que parece "una tercia naturaleza" (VI, 345).

Junto a otro séquito de pastores que se les une durante el camino, llegan al Valle de los Cipreses, un lugar idílico donde, entre fuentes y árboles, se halla una galería de tumbas: "algunas sepulturas, cuál de jaspe y cuál de mármol fabricada, en cuyas blancas piedras se leían los nombres de los que en ella estaban sepultados", entre las que destaca "la triste sepultura donde reposan los honrados huesos del nombrado Meliso, honor y gloria de nuestras riberas", que se encontraba en un lugar especial ("apartada de las otras, a un lado de la ancha plaza") y compuesta con todo primor de "lisas y negras pizarras y de blanco y bien labrado alabastro" (VI, 348) 4 .

Con esta mínima descripción, Telesio abre fuego con un primer encomio de Meliso:

con maravillosa elocuencia comenzó a alabar las virtudes de Meliso, la integridad de su inculpable vida, la alteza de su ingenio, la entereza de su ánimo, la graciosa gravedad de su plática y la excelencia de su poesía; y, sobre todo, la solicitud de su pecho en guardar y cumplir la santa religión que profesado había, juntando a estas otras tantas y tales virtudes de Meliso que, aunque el pastor no fuera tan conocido de todos [...], solo por lo que él decía quedaran aficionados a amarle si fuera vivo, y a reverenciarle después de muerto (VI, 349).

En verdad, este elogio en discurso indirecto es únicamente el aperitivo que prepara e invita a la celebración de "las frías cenizas de Meliso [...] con más reposada y sonora voz" por parte de los pastores (VI, 350). Más allá de la alabanza general, Telesio da pie directamente a la elegía a cuatro voces de Tirsi, Elicio, Damón y Lauso, "tan conocidos amigos y familiares" de Meliso (VI, 350), que son máscaras pastoriles de Cervantes y otros ingenios cortesanos que refuerzan el valor contextual del poema ${ }^{5}$.

De nuevo, la intervención se prepara cuidadosamente con algunos instrumentos rústicos que puntean "una tan triste y agradable música", acorde con "la dulce armonía de los pintados y muchos pajarillos que por los aires cruzaban, y algunos sollozos de las pastoras" que en conjunto formaban "un tan estraño y lastimoso concento que no hay lengua que encarecerlo pueda" (VI, 350).

${ }^{4}$ Para la dimensión artística del pasaje, ver De Armas (2004).

${ }^{5}$ Según esta red de relaciones, se trata de Cervantes (Lauso), Laínez (Damón) y Figueroa (Tirsi), más un eco garcilasiano al pastor Salicio (Elicio). 
La "Elegía por Meliso" es un poema polifónico en tercetos que arranca con un exordio sobre la tristeza del canto (vv. 1-6), prosigue con el lamento por la muerte de Meliso (vv. 7-48) con una apelación a la muerte (vv. 25-30) y consideraciones sobre la fugacidad de la vida (vv. 34-48), el elogio del curriculum vitae del personaje (vv. 49-60) como embajador en Venecia (vv. 49-51), un trágico giro de la fortuna (vv. 52-54) y el retiro ("sosiego reposado") posterior dedicado a la poesía (vv. 55-60), para retomar la expresión de dolor y el consuelo que deja tanto su memoria como su paso a una mejor vida (vv. 61-157), que se cierra con una suerte de resumen final:

En tu sabiduría se enseñaban

los rústicos pastores, y en un punto,

con nuevo ingenio y discreción quedaban.

Pero llegose aquel forzoso punto

donde tú te partiste y do quedamos

con poco ingenio y corazón difunto.

Esta amarga memoria celebramos

los que en la vida te quisimos tanto

cuanto ahora en la muerte te lloramos.

(vv. 136-144)

El poema es todo un éxito, pues "la triste y dolorosa elegía" deja al auditorio "sin que le pusiesen [fin] por un buen espacio a las lágrimas todos los que el lamentable canto escuchado habían" (VI, 357), tras lo que se terminan las exequias con una invitación anacreóntica a la comida, que luego dará paso a la aparición de Calíope y su canto parnasiano 6 . Si es claro que la "Elegía por Meliso" no es un epitafio stricto sensu, en el contexto de la novela hace las veces de poema sepulcral, en alianza con la ocasión fúnebre y el discurso de Telesio, al tiempo que concede un lugar de honor a un poeta muy caro a Cervantes (Hurtado de Mendoza) que — ya muerto- no podía aparecer en el "Canto de Calíope".

En este orden de cosas, además, esta elegía pastoril se relaciona con el soneto "A don Diego de Mendoza y a su fama" (núm. 29) que Cervantes diseña para la edición de las Obras (Madrid: Juan de la Cuesta, 1610 [1609]) del poeta, empresa en la que estuvo muy activo (Rico 2002; Blecua 2005): ambos poemas inciden una y otra vez en la inmortal memoria del personaje y elogian su poética amorosa ("casta llama"), junto a unos pocos lazos intertextuales:

Repítanse los versos que ha cantado, queden en la memoria de las gentes por muestras de su ingenio levantado. (vv. 98-100)

Y de su casta y amorosa llama ejemplo tome el más lascivo pecho y el que en ardor menos cabal se inflama. (vv. 103-105)

\author{
En la memoria vive de las gentes, \\ varón famoso, siglos infinitos, \\ premio que le merecen tus escritos \\ por graves, puros, castos y excelentes. \\ (vv. 1-4)
}

\author{
Las ansias en honesta llama ardientes, \\ los Etnas, los Estigios, los Cocitos \\ que en ellos suavemente van descritos, \\ mira si es bien, joh, Fama!, que los cuentes. \\ (vv. 5-8)
}

${ }^{6}$ De hecho, este encomio poético se relaciona desde el preámbulo en prosa de la ninfa con el homenaje funeral: "os prometo, [...] en pago del beneficio que a las cenizas de mi querido y amado Meliso habéis hecho, de hacer siempre que en vuestras riberas jamás falten pastores que en la alegre ciencia de la poesía a todos los de las otras riberas se aventajen" (VI, 361). Así también lo reafirma Telesio, quien mantiene que el lance caliopesco muestra "cuán acepta es al cielo la loable costumbre que tenemos de hacer esos anales sacrificios y honrosas obsequias por las felices almas de los cuerpos que por decreto vuestro en este famoso valle tener sepultura merecieron" (VI, 396). 
Si bien es posible que la elegía sea una composición cercana a la muerte de Hurtado de Mendoza (1575) luego recogida en La Galatea tras el hiato del cautiverio, lo que sí es seguro es que Cervantes recupera el modelo de este poema para elaborar el soneto posterior.

\section{LOS EPITAFIOS DEL QUIJOTE (Y ALGO MÁS)}

El Quijote es una novela nacida bajo el signo de la muerte: de antemano se sabe que don Quijote es de otro mundo ("no ha mucho tiempo que vivía", I, 1), el personaje declara haber nacido "para vivir muriendo" (II, 59), parece morir en alguna ocasión y la escena final ofrece un ejemplo de buena muerte (Sáez 2012a). Pero no hay que esperar tanto: ya en el primer Quijote se desvela el "fin y acabamiento" del caballero con el hallazgo de la caja de plomo con su sepultura y epitafios (I, 52), cierre que determina que la segunda entrega comience con don Quijote "finalmente muerto y sepultado" (prólogo).

Con todo, antes del manojo de poemas a la muerte de don Quijote se encuentran otras poesías fúnebres. Sin duda, la "Canción desesperada" de Grisóstomo (I, 14) es una apertura dorada para esta galería poética, que se inscribe dentro del primer contacto del caballero con el mundo pastoril, introducido progresivamente: luego de la cena con los cabreros con el discurso de la Edad Dorada y un poema de Antonio (I, 11), sigue el relato de la historia de Marcela y Grisóstomo (I, 12) que enlaza con la entrada en escena de la aventura y la "Canción desesperada" (I, 13-14), que rompe en pedazos el ambiente bucólico, si bien se compensa en cierta medida porque la muerte ha tenido lugar fuera de la acción. Igualmente, este poema es la cruz trágica del universo pastoril, en contraste directo con la cara "realista" del romance de Antonio (I, 11) y el canto burlesco de unas coplas de don Quijote (I, 26).

Todavía con más fuerza que la "Elegía por Meliso", este largo poema se inscribe en la celebración de una muerte, pues si los pastores galateicos conmemoraban un hecho previo, la canción se enmarca directamente en el entierro del pastor Grisóstomo. También esta vez comienza todo con un cortejo popular ("veinte pastores", I, 14) que crece por momentos ("seis pastores" más, I, 13) en hábito de luto ("con pellicos de negra lana vestidos y coronados con guirnaldas, [...] cual de tejo y cual de ciprés", I, 14) que está coordinado por un personaje (Ambrosio), "un maravilloso silencio" acorde a la ocasión y un lugar especial:

Allí [...] vio la vez primera a aquella enemiga mortal del linaje humano, y allí fue también donde la primera vez le declaró su pensamiento, tan honesto como enamorado, y allí fue la última vez donde Marcela le acabó de desengañar y desdeñar, de suerte que puso fin a la tragedia de su miserable vida. Y aquí, en memoria de tantas desdichas, quiso él que le depositasen en las entrañas del eterno olvido (I, 13).

Igual que Telesio, Ambrosio proclama un primer elogio del pastor, que aúna el encomio con la crítica a la pastora, en unas palabras que ganan en patetismo frente al cadáver de Grisóstomo:

Ese cuerpo, señores, que con piadosos ojos estáis mirando, fue depositario de un alma en quien el cielo puso infinita parte de sus riquezas. Ese es el cuerpo de Grisóstomo, que fue único en el ingenio, solo en la cortesía, estremo en la gentileza, fénix en la amistad, magnífico sin tasa, grave sin presunción, alegre sin bajeza, y, finalmente, primero en todo lo que es ser bueno, y sin segundo en todo lo que fue ser desdichado. Quiso bien, fue aborrecido; adoró, fue desdeñado; rogó a una fiera, importunó a un mármol, corrió tras el viento, dio voces a la soledad, sirvió a la ingratitud, de quien alcanzó por premio ser despojos de la muerte en la mitad de la carrera de su vida, a la cual dio fin una pastora a quien él procuraba eternizar para que viviera en la memoria de las gentes (I, 13).

Tras la introducción en prosa, viene nuevamente un correlato poético a modo de segunda parte que, en este caso, se compone de un poema de Grisóstomo (la "Canción desesperada") y un epitafio final. Esta "Canción desesperada" forma parte de los papeles del pastor, que estaban con- 
denados al fuego pero la petición de otros personajes logra que se salven algunos ${ }^{7}$. Más en detalle, se trata del "último papel que escribió el desdichado" (I, 13) y se lee en voz alta a todo el auditorio, en otro ejemplo de la oralidad del Quijote.

En breve, este poema ofrece una versión de la historia que justifica la muerte del enamorado, según el modelo de la canzone disperata (Alonso 2008): luego de la apertura sobre la necesidad del doloroso canto (vv. 1-16), vienen consideraciones sobre el estilo duro de la canción mediante enumeraciones y comparaciones animalísticas (vv. 17-48), el lamento por el desamor (vv. 49-80) y el deseo de morir como único remedio (vv. 81-128), para acabar con una invocación final al poema (vv. 129-133) ${ }^{8}$. En general, la nota predominante es el dolor del poeta-amante, que a un tiempo está "celoso, ausente, desdeñado y cierto" (v. 57) y llega a mezclar "pedazos de las míseras entrañas" (v. 11) entre verso y verso.

En el centro del poema se encuentra el suicidio del personaje, que ya se adivina en las curiosas condiciones del entierro ("en el campo, como si fuera moro", con otras cláusulas que "parecen de gentiles", I, 12) y queda claro en el poema, que actúa como la nota de despedida de un suicida (Sáez 2015: 213):

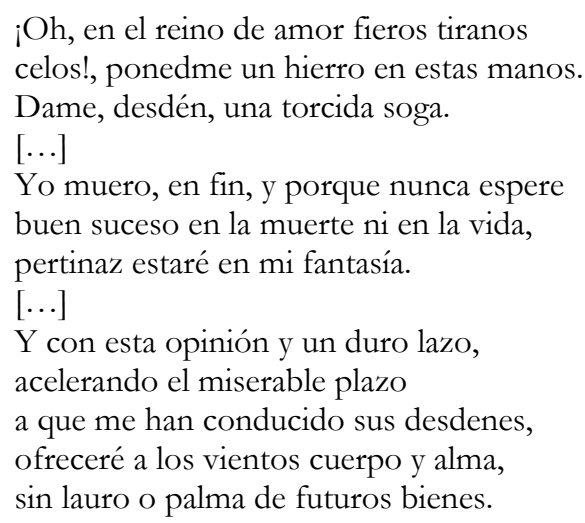

$$
\text { (vv. 76-78, 81-83 y 92-96) }
$$

Ciertamente, el poema vale como la despedida de Grisóstomo, que llega a indicar una última relación con la tumba ("aun en la sepultura no estés triste", v. 133) que robustece el carácter funeral del poema, y abre la puerta al epitafio final del pastor.

Entre medias, el tono cambia radicalmente con la aparición de la pastora Marcela y su defensa de la libertad femenina, tanto que solamente una intervención de don Quijote impide que los pastores vayan tras ella. Restaurada la calma, prosigue el entierro de Grisóstomo, con la quema de sus papeles y los últimos retoques de la sepultura, que se cierra con "una gruesa peña" como solución temporal hasta que se termine una "losa" en la que debería de constar un epitafio, seguramente —aunque no se dice— obra de Ambrosio:

\footnotetext{
Yace aquí de un amador el mísero cuerpo helado, que fue pastor de ganado, perdido por desamor. Murió a manos del rigor
}

7 También se nombra como "Canción de Grisóstomo" y "Versos desesperados". Obviamente, late el modelo de Virgilio y la Eneida (Marasso 1947: 46-47). Más adelante, pretenden leer "otro papel de los que había reservado del fuego", pero la llegada de Marcela lo impide (I, 14).

${ }^{8}$ Esta coda metapoética se repite en las dos canciones a la Armada (núms. 19-20) y en otra "A los éxtasis de nuestra Bendita Madre Teresa de Jesús" (núm. 32). 
de una esquiva hermosa ingrata, con quien su imperio dilata

la tiranía de amor.

Esta octavilla, que concluye las exequias pastoriles junto a las flores de rigor, es una respuesta al parlamento de Marcela, que vuelve a la visión negativa inicial de la pastora, acorde con la "Canción desesperada". En otro sentido, se trata del primer epitafio con todas las de la ley de las novelas cervantinas, pues sigue al pie de la letra el patrón básico con el incipit lapidario ("Hic iacet...”), la presentación del relato (narratio) de las causas (mal de amores) de la muerte del personaje (con guiño cómico al "pastor [...] / perdido", vv. 3-4) y el cierre ingenioso que conecta el caso concreto con una lección universal (la fuerza tiránica del amor).

Sigue un díptico de sonetos de corte bélico ("el de la Goleta" y "el del fuerte", I, 39-40):

\begin{abstract}
Almas dichosas que del mortal velo
libres y esentas, por el bien que obrastes, desde la baja tierra os levantastes a lo más alto y lo mejor del cielo, $\mathrm{y}$, ardiendo en ira y en honroso celo, de los cuerpos la fuerza ejercitastes, que en propia y sangre ajena colorastes el mar vecino y arenoso suelo: primero que el valor faltó la vida en los cansados brazos, que, muriendo, con ser vencidos, llevan la vitoria; y esta vuestra mortal, triste caída entre el muro y el hierro, os va adquiriendo fama que el mundo os da, y el cielo gloria.
\end{abstract}

De entre esta tierra estéril, derribada, destos terrones por el suelo echados, las almas santas de tres mil soldados subieron vivas a mejor morada, siendo primero en vano ejercitada la fuerza de sus brazos esforzados, hasta que al fin, de pocos y cansados, dieron la vida al filo de la espada. $\mathrm{Y}$ este es el suelo que continuo ha sido de mil memorias lamentables lleno en los pasados siglos y presentes. Mas no más justas de su duro seno habrán al claro cielo almas subido, ni aun él sostuvo cuerpos tan valientes.

$(\mathrm{I}, 40)$

Dentro de la novela son dos poemas compuestos por el alférez Pedro de Aguilar, compañero de fatigas del capitán Pérez de Viedma, y funcionan como signo de anagnórisis y como marca de cierre de la etapa militar del personaje, que comienza sus desventuras del cautiverio (Sáez 2016b). Asimismo, estas dos poesías "a manera de epitafios" (I, 39) poseen un profundo valor autobiográfico como recuerdo poético de una trágica acción contemplada en primera persona, al tiempo que se enmarcan en una moda de poemas heroicos sobre hechos bélicos contemporáneos.

Según Ponce Cárdenas (2016: 143-174), en este dueto sonetil apenas se hallan algunos motivos típicos de la retórica epitáfica, justamente porque ambos pertenecen a la modalidad del epitafio heroico, que se centra en el elogio con toques de terribilità y tonos oscuros de los héroes caídos por la patria, que se configura a partir de una serie de modelos italianos (con Tansillo a la cabeza).

En el marco de los epitafios cervantinos, los sonetos a la caída de La Goleta disfrutan de un lugar especial por al menos tres razones: primero, constituyen una celebración colectiva ("Almas dichosas", v. 1; "tres mil soldados", v. 3) frente a la tónica individual, de acuerdo con la empresa cantada; asimismo, interesa la notable dimensión religiosa del encomio, que acerca a los mílites al mar-

${ }^{9}$ En palabras de Jehenson $(1990,30)$, «On Grisóstomo’s epitaph [...] remains — for posterity — what they had said she was in the first place». Otras ideas en Montero Reguera (2012, 394-396), que indica que «[1]a novela pastoril era lugar abonado para la inclusión de epitafios» (396, n. 20), en la estela del modelo de La Diana (1559) de Montemayor. 
tirio; y, tercero y en perfecta sintonía con la visión providencialista, la derrota se convierte paradójicamente en un triunfo ("con ser vencidos, llevan la vitoria", v. 11) que ofrece consuelo, de modo parecido a las dos canciones cervantinas a la Gran Armada (núms. 19-20).

No obstante, la verdadera revolución cervantina con el esquema de la poesía funeral se encuentra al final del primer Quijote, con la galería de epitafios burlescos de los académicos de Argamasilla, que cierran el círculo de los poemas preliminares a la vez que dan una vuelta de tuerca jocosa a la poética fúnebre, en una nueva muestra de la afición cervantina a jugar y retorcer todos los modelos a su alcance. Es cierto que este grupo poético aparece al alimón que una gavilla de epitafios jocosos recogidos en las Flores de poetas ilustres (Valladolid: Luis Sánchez, 1605), de Espinosa, pero la fuerza de la sátira cervantina parece "el asesinato de una tradición epigráfica venerable para todo buen humanista", a decir de Márquez Villanueva (1995: 135).

Este ciclo de poemas forma parte del final sin final de la novela, que deja algunas líneas abiertas mediante la estrategia de "una caja de plomo" con unos misteriosos pergaminos que contenían nuevas hazañas de don Quijote junto a "diferentes epitafios y elogios de su vida y costumbres" (I, 52), que vienen a ser los sonetos burlescos de los académicos Monicongo, Paniaguado, Caprichoso, Burlador, Cachidiablo y Tiquitoc, que son todos los que están, pero no están todos los que son: "Estos fueron los versos que se pudieron leer", mientras que los demás, "por estar carcomida la letra, se entregaron a un académico para que por conjeturas los declarase” (I, 52).

Por de pronto, este sexteto poético constituye un cierre en falso, tanto porque parece despedir la novela sin plan de continuación alguna como porque la "resurrección" de los personajes en el segundo Quijote refuerza el carácter burlesco de las poesías. Al igual que otras veces, Cervantes se divierte en hacer saltar por los aires las convenciones habituales de esquemas poéticos de moda: en este caso, el dardo cervantino apunta directamente contra la poesía de academia, con la ficción autorial de los ridículos poemas que contienen insulto tras insulto a los personajes de la novela como en un ejercicio de vejamen académico. Así, esta versión paródica de una academia es una crítica que traduce tanto el alejamiento de Cervantes de estos círculos literarios como su apuesta poética frente al estado coetáneo del campo literario (Martín 1991: 147-156; Márquez Villanueva 1995).

El artificio chistoso comienza desde el principio, pues la Academia de Argamasilla deriva de "argamasa", que vale 'duro' y niega toda capacidad ingeniosa para la poesía, de la misma manera que los nombres de sus miembros son un puro chiste, con los que Cervantes ofrece "una risueña tipología de los bajos fondos académicos en todo tiempo y lugar": si uno es sinónimo de rudeza (Monicongo), otro representa a los poetas favorecidos y pensionados (Paniaguado), el siguiente es un poeta que no se atiene a las normas (Caprichoso), uno más vale como emblema de los ingenios maliciosos (Burlador), otro parece encarnar a un plagiario (Cachidiablo) y el último a un ingenio de segunda fila — quizá tan insoportable como el ruido de un reloj- (Tiquitoc), mientras que en el centro se encontraría don Quijote como presidente del encuentro (Márquez Villanueva 1995: 132133).

El corpus se compone de tres epitafios (Monicongo, Cachidiablo y Tiquitoc) por otros tantos elogios (Paniaguado, Caprichoso, Burlador). El primer poema ya da la tónica general del conjunto: el epitafio de Monicongo, "A la sepultura de don Quijote", ofrece una andanada de insultos contra el caballero, desde "calvatrueno" ('calvo' y 'loco', v. 1) a veleta (vv. 3-4), en un aparente y chistoso elogio de superación de los modelos clásicos y caballerescos que se remata con una sentencia típica de la retórica funeral ("yace debajo desta losa fría", v. 14), que Cervantes aprovecha en otro soneto a Herrera (núm. 28, v. 14). Los otros dos siguen la misma dinámica entre la norma y la desviación jocosa: con un arranque convencional de la poesía funeral ("Aquí yace...", "Reposa aquí..."), en los epitafios "En la sepultura de don Quijote" (Cachidiablo) y "En la sepultura de Dulcinea del Toboso" (Tiquitoc) se injuria burlescamente a los personajes, pues en el primero don 
Quijote se ridiculiza como "caballero / bien molido y malandante" (vv. 1-2) y en el segundo Dulcinea se describe como gorda ("de carnes rolliza", v. 2) y de origen poco claro ("de castiza ralea" y con "asomos de dama", v. 5-6). Además, en el epitafio a don Quijote hay también lugar para Rocinante y Sancho Panza, "el majadero" (v. 5), en un nuevo ejemplo de encomio plural que deja especialmente en buen lugar al "escudero [...] más fiel / que vio el trato de escudero" (vv. 7-8).

Por el contrario, los otros tres sonetos son elogios comme il faut con una cierta dosis de broma: el soneto "In laudem Dulcineae del Toboso" del Caprichoso empieza con el guiño pedantesco del latín para seguir con un retrato grotesco del personaje, que se pinta con rostro deforme ("amondongado", v. 1) y excesivamente carnal ("alta de pechos", v. 2, con sentido múltiple); el poema "En loor de Rocinante" es un elogio al uso que no revela el nombre del caballo hasta el final (v. 16) y añade la forma del soneto con estrambote que tan bien dominaba Cervantes; a su vez, en el texto "A Sancho Panza" del Burlador se traza un elogio juguetón con algún contraste ("[...] en cuerpo chico, / pero grande en valor", vv. 1-2) e ironías ("escudero el más simple y sin engaño", v. 3) que acaba con un homenaje final a Góngora ("y al fin paráis en sombra, en humo, en sueño", v. 14). Así las cosas, los poemas argamasillescos son tanto una crítica contra los textos de academia como un buen botón de muestra de las dos variantes principales (panegírico y vituperio) del epitafio.

Después de este ramillete poético-funeral poco más se podía —y debía - añadir, por lo que el segundo Quijote carece de epitafios hasta el final del personaje y la novela, y tampoco media en este campo ninguna aportación de Avellaneda. Todo acaba con los poemas sobre la muerte de don Quijote, que se componen de una serie de "nuevos epitafios de su sepultura" que se omiten ("Déjanse de poner") y el texto de Sansón Carrasco, que hace pareja tanto con los epitafios argamasillescos como con las palabras de Cide Hamete a su pluma (“Tate, tate, folloncicos!”, II, 74), que cierran con doble candado - y por si acaso— toda posible continuación ${ }^{10}$ :

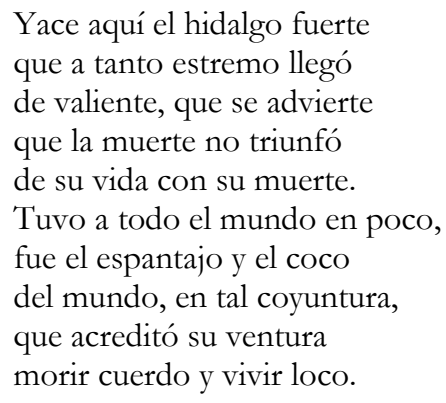

Con este epitafio, Cervantes retoma el esquema esencial ya manejado en el poema a Grisóstomo (I, 14, ver supra) con la apertura convencional con la fórmula sepulcral ("Hic iacet...", v. 1), para después realizar un encomio burlesco que desmonta la digna muerte de don Quijote: así, primeramente está la celebración de la valentía del personaje, que le concede fama con la que superar a la muerte (vv. 1-5), para continuar con un contrapunto chistoso formado por juegos ambiguos ("vencer a todos" o "despreciarlos", v. 6), un par de pullas sobre la estrafalaria figura del caballero ("espantajo", "coco", v. 7) y un remate paradójico ("morir cuerdo y vivir loco", v. 10). La tensión entre el elogio y la burla representa bien la actitud del bachiller Carrasco frente a don Quijote, al tiempo que casa a las mil maravillas con el carácter baciyélmico del caballero (Fernández: 2005) ${ }^{11}$.

${ }^{10}$ Con estos textos epitáficos tal vez se aluda a la serie de poemas argamasillescos que no se habían podido presentar en la primera entrega y se prometían para mejor ocasión, aunque quizá apunte a un nuevo ejemplo de textos fantasmas del Quijote, que únicamente se insinúan, como un poema de don Quijote (I, 26), ciertas "coplitas y estrambotes" de don Clavijo (II, 38), etc.

11 Ver más en Montero Reguera (2012: 404-405). 


\section{PUNTO Y FINAL: UN EPITAFIO EN PROSA}

Para cerrar la cosa, con la aportación del Persiles a esta galería de poemas fúnebres Cervantes riza el rizo con una versión en prosa, que en cierto sentido ya se anunciaba en esa joya que es el prólogo de la novela, cuando se expresaba al borde de la muerte y se despedía con una suerte de epitafio en vida: "el tiempo es breve, las ansias crecen, las esperanzas menguan, y, con todo esto, llevo la vida sobre el deseo que tengo de vivir" (108).

Sea como fuere, esta inscripción sepulcral en prosa es la conclusión de la historia de Manuel de Sosa Coutiño (o Coitiño), una novelita de amor trágico que se desarrolla en dos etapas con el relato autobiográfico del soldado y la coda del epitafio: primero, se conoce el soneto cantado en portugués y castellano "Mar sesgo, viento largo, estrella clara" (I, 9) (Lozano-Renieblas: 2004), al que sucede el relato de las desventuras amorosas del personaje con Leonora y la muerte del personaje ("dando un gran suspiro, se le salió el alma y dio consigo en el suelo", I, 10, 196), que deja asombrado y conmovido a todo el auditorio, que decide darle rústica sepultura (con su vestido "por mortaja", la nieve por tierra y de cruz el símbolo de la Orden de Christus); y, segundo, viene la pequeña continuación con el conocimiento de la recepción de las malas nuevas en casa de los Sosa Coutiño ${ }^{12}$.

Del epitafio tienen noticia en Lisboa gracias a otro de los prisioneros de los bárbaros, que les informa que un hermano de Sosa Coutiño hizo celebrar sus exequias y mandó poner un poema tan "discreto" como "gracioso" en "una capilla de su linaje [...] en una piedra de mármol blanco, como si debajo della estuviera enterrado" (III, 1, 436). Así, se trata de un epitafio in absentia, que se presenta en un sepulcro vacío. Como el soneto de Sosa Coutiño, es una composición originalmente en portugués que traduce "casi en castellano" Antonio el padre durante su lectura viva voce:

Aquí yace viva la memoria del ya muerto Manuel de Sosa Coitiño, caballero portugués, que, a no ser portugués, aún fuera vivo. No murió a las manos de ningún castellano, sino a las de amor, que todo lo puede. Procura saber su vida y envidiarás su muerte, pasajero (III, 1, 436).

Para empezar, Cervantes parece hacer un guiño a la variedad de los epitafios jocoserios en portugués que circulaban en diversas antologías (Pedrosa 2007: 102) y que dieron pie a versiones paródicas de todo pelo (valga Quevedo con "Aquí yace un portugués”), pues se dice que "en el escribir de los cuales [los epitafios] tiene gran primor la nación portuguesa" (III, 1, 436). Pero hay más: el epitafio prosístico sigue el esquema funeral habitual con el inicio lapidario ("Aquí yace") que juega — paradoja mediante - con la vida de la memoria y la muerte del personaje, la presentación del difunto (nombre, condición y nación), la descripción de las razones de "la enamorada muerte" (III, $1,435)$ según la imagen tópica de los portugueses con un guiño a la tradicional rivalidad hispanolusitana ("No murió a manos de ningún castellano") emparejado con un recuerdo virgiliano ("omnia vincit amor") y la adición de una apelación al peregrino ("Procura saber su vida y envidiarás su muerte, caminante"), un elemento de la retórica funeral que Cervantes deja de lado por norma general.

\section{INSCRIPTIO FINAL}

En resumen, el repaso de las poesías funerales novelescas cervantinas refleja la vitalidad de un esquema poético bien conocido en su día, con el que Cervantes se atreve a experimentar dentro de relatos en prosa, con todo lo que eso conlleva. Aunque no siempre queda claro si los poemas están antes que las novelas (como parece ocurrir con la "Elegía por Meliso" y la "Canción desespera-

12 Otros detalles se pueden ver en Roig (2004) y Zimic (2005: 38-46). Para Alcalá Galán (1999: 34) el poema del portugués tiene más relación con el tema general de la novela que con su historieta. 
da") o viceversa, cada poesía adquiere todo su sentido por la unión con la acción general, hasta el extremo de que el último ejemplo es un verdadero epitafio prosístico.

Especialmente se aprecia que los poemas novelescos sobre la muerte carecen de un valor contextual conectado con los intereses cervantinos, seguramente porque la mirada se centra en los lazos con la ficción. Quizá así se explique el carácter excepcional de la "Elegía por Meliso" de La Galatea, un poema algo "pegadizo" — para decirlo cervantinamente- sobre un pastor ausente de la acción que representa a un ingenio cortesano cercano a las esferas de poder a las que Cervantes intentaba arrimarse en sus años mozos, con el décalage de una década entre la muerte del personaje y la aparición de la novela. En este sentido, se puede apreciar una cierta evolución hacia la autonomía desde la "Elegía por Meliso" y la "Canción desesperada", que viven íntimamente unidos a los marcos narrativos, frente a la mayor libertad de otras poesías posteriores.

El conjunto de poemas funerales novelescos abarca una elegía, una versión hispánica de la canzone disperata y una serie de epitafios tanto serios como burlescos, galería con la que Cervantes toca las variedades principales de la poética funeral tanto en el sujeto (encomio de hombres de armas y letras) como en la intención (del elogio al chiste), y quizá una mayor cercanía al esquema lapidario habitual, con los inicios sepulcrales ("Hic iacet...") a la orden del día y hasta una excepcional apelación al caminante en el epitafio en prosa del Persiles. Igualmente, se confirman otros patrones poéticos cervantinos, como la descarada preferencia cervantina por el soneto, modelo del que apenas se desgajan los dos grandes poemas fúnebres (la "Elegía por Meliso" y la "Canción de Grisóstomo"), tres octavillas (epitafios a Grisóstomo, don Quijote y Dulcinea) y una quintilla (epigrama del bachiller Carrasco), más la coda en prosa del Persiles, que va por libre; a la par, se remacha el gusto de Cervantes por la composición de poemas en parejas (la pareja bélica del capitán cautivo, pero también la canción de Grisóstomo y el epitafio de Ambrosio) y otras series mayores (los sonetos argamasillescos), con una escisión postrera entre poemas orales y escritos según el soporte en el que se presentan. Si "morir sin más ni más" es "la mayor locura que puede hacer un hombre en esta vida" (II, 74), acaso poetizar la muerte sea tanto una suerte de nueva vida como una buena manera de decir adiós. 


\section{OBRAS CITADAS}

AlCALÁ GaLÁN, Mercedes (1999 [2009]): “Teoría de la poesía en Cervantes: poesía citada en la novela". Caliope: Journal of the Society for Renaissance and Baroque Hispanic Poetry, 5. 2. 27-43. [Después en Escritura desatada: poéticas de la representación en Cervantes. Alcalá de Henares: Centro de Estudios Cervantinos. 179-196.]

Alonso, Álvaro (2008): "La canción desesperada de Cervantes: cancioneros, modelos italianos y sensibilidad romántica", en Juan Matas Caballero y José María Balcells (ed.). Cervantes y su tiempo. León: Universidad de León. 109-121.

BLECUA, Alberto (2005): "La epístola al lector a la edición de las Obras de Hurtado de Mendoza (Madrid, 1610): ¿un viejo-nuevo texto cervantino?”. Ínsula, 700-701. 2-6.

Cervantes, Miguel de (1997): Los trabajos de Persiles y Sigismunda. Edición de Carlos Romero Muñoz. Madrid: Cátedra.

- (2013): Novelas ejemplares. Edición de Jorge García López. Madrid: RAE.

- (2014): La Galatea. Edición de Juan Montero, Francisco J. Escobar Borrego y Flavia Gherardi. Madrid: RAE.

- (2015): Don Quijote de la Mancha. 2 vols. Edición dirigida por Francisco Rico. Madrid: RAE.

- (2016): Poesías, Edición de Adrián J. Sáez: Madrid. Cátedra.

DE ARMAS, Frederick A. (2004): "De pinturas, fuentes y sepulcros en La Galatea, VI: el maravilloso jardín de Meliso”, en Kurt y Eva Reichenberger(ed.). Cervantes y su mundo. Vol. 1. Kassel: Reichenberger. 21-32.

DÍEZ FERNÁNDEZ, José Ignacio (1996): "Funciones de la poesía en Los trabajos de Persiles y Sigismunda'. Dicenda: Cuadernos de Filología Hispánica, 14. 93-112.

FERNÁNDEZ, Jaime S. J. (2005): "La verdad del epitafio para la tumba de don Quijote”, en Chul Park (ed.). Actas del XI Coloquio Internacional de la Asociación de Cervantistas (Seúl, 17-20 de noviembre de 2004). Seúl: Universidad Hankuk de Estudios Extranjeros. 463-475. [Disponible en la Biblioteca Virtual Miguel de Cervantes, en red: $<$ https://cvc.cervantes.es/literatura/cervantistas/cl_XI.htm>.]

GIL-OsLe, Juan Pablo (2013): Amistades imperfectas: del Humanismo a la Ilustración con Cervantes. Madrid/Frankfurt: Iberoamericana/Vervuert.

Jehenson, M. Yvonne (1990): “The Pastoral Episode in Cervantes' Don Quijote: Marcela Once Again". Cervantes: Bulletin of the Cervantes Society of America, 10. 2. 15-35.

LLAMAS MARTÍNEZ, Jacobo (2016): Tradición y originalidad en la poesía funeral de Quevedo. Vigo: Academia del Hispanismo.

López PozA, Sagrario (2008): "El epitafio como modalidad epigramática en el Siglo de Oro (con ejemplos de Quevedo y Lope de Vega)". Bulletin of Hispanic Studies, 85. 6. 821-838.

LOZANO-RENIEBLAS, Isabel (2004): “Mar sesgo, viento largo, estrella clara' o la metáfora de la nave de amor en el Persiles". Anales Cervantinos, 36. 299-308.

Marasso, Arturo (1947): Cervantes. Buenos Aires. Academia Argentina de Letras. 1947. Disponible en la Biblioteca Virtual Miguel de Cervantes, en red: $<$ http://www.cervantesvirtual.com/obra/cervantes-1/>].

MARÍn CEPEDA, Patricia (2015): Cervantes y la corte de Felipe II: escritores en el entorno de Ascanio Colonna (1560-1608). Madrid: Polifemo.

MÁrQuez Villanueva, Francisco (1995 [1987]): “El mundo literario de los Académicos de la Argamasilla”. Trabajos y días cervantinos. Alcalá de Henares: Centro de Estudios Cervantinos. 115155. [Antes en La Torre, 1. 9-43.]

- (2005 [1995]): "Sobre el contexto religioso de La Galatea". Cervantes en letra viva: estudios sobre la vida y la obra. Barcelona: Reverso. 171-191. [Antes en Giuseppe Grilli (ed.). Actas del II Congreso 
Internacional de la Asociación de Cervantistas (Nápoles, 4-9 de abril de 1994). Napoli: Istituto Universitario Orientale. 181-196.]

MARTíN, Adrienne L. (1991): Cervantes and the Burlesque Sonnet. Berkeley: University of California Press.

Montero Reguera, José (2011): “Trayectoria del epitafio en la poesía cervantina, I”, en Christoph Strosetzki (ed.). Visiones y revisiones cervantinas: Actas selectas del VII Congreso Internacional de la Asociación de Cervantistas. Alcalá de Henares: Centro de Estudios Cervantinos. 629-638. [Disponible en la Biblioteca Virtual Cervantes: $<$ https://cvc.cervantes.es/literatura/cervantistas/cg_VII.htm>.]

- (2012): "Trayectoria del epitafio en la poesía cervantina". eHumanista/Cervantes, 1. 388-410. [En red:

$<$ https://www.ehumanista.ucsb.edu/sites/secure.lsit.ucsb.edu.span.d7_eh/files/sitefiles/cer vantes/volume $1 / 22 \% 20$ montero.pdf $>$.

PedrosA, José Manuel (2007): "El otro portugués: tipos y tópicos en la España de los siglos XVI al XVIII», en Tobias Brandenberger (coord.). España y Portugal: antagonismos literarios e históricos (siglos XVI al XVIII). Iberoamericana, 7. 28. 99-116.

PONCE CÁRDENAS, Jesús (2014): “El epitafio hispánico en el Renacimiento: texto y contextos”. eSpania: revue interdisciplinaire d'études hispaniques medievales et modernes, 17. s. p. [En red: $<$ https://journals.openedition.org/e-spania/23300>.]

- (2016): La imitación áurea (Cervantes, Quevedo, Góngora). Paris: Éditions Hispaniques.

RiCO, Francisco (2002): “A pie de imprentas: páginas y noticias de Cervantes viejo”. Bulletin Hispanique, 104. 2. 673-702.

RoIG, Adrien (2004): "De la vida de Manuel de Sousa Coutinho al 'triste y no imaginado suceso' del portugués que murió de amor en el Persiles". Alicia Villar Lecumberri (ed.). Peregrinamente peregrinos: Actas del V Congreso Internacional de la Asociación de Cervantistas. Vol. 1. Barcelona: Asociación de Cervantistas. 879-898. [Disponible en la Biblioteca Virtual Miguel de Cervantes, en red: <https://cvc.cervantes.es/literatura/cervantistas/cg_V.htm>.]

Ruiz PÉREZ, Pedro (2010): “El 'Canto de Calíope': entre la Arcadia, el Parnaso y la república literaria». M. ${ }^{a}$ Carmen Marín Pina (coord.). Cervantes en el espejo del tiempo. Zaragoza: Universidad de Zaragoza. 393-429.

SÁEZ, Adrián J. (2012a): "De Cervantes a Quevedo: testamento y muerte de don Quijote". La Perinola, 16. 239-258.

- (2012b): "De muerte y locura: tres acotaciones sobre el final del Quijote". Anuario de Estudios Cervantinos, 8. 105-122.

— (2015): “Un 'pecado tan malo y feo': variaciones cervantinas sobre el suicidio”. Iberoromania, 82. 202-217.

— (ed.) (2016a): Miguel de Cervantes. Poesías. Madrid. Cátedra.

- (2016b): "Vida del capitán Ruy Pérez de Viedma: la autobiografía soldadesca en Don Quijote (I, 39)". Cervantes: Bulletin of the Cervantes Society of America, 36. 1. 85-104.

- (en prensa): “'Sentir callando': la poesía funeral de Cervantes”. Rilce: revista de filología hispánica.

ZIMIC, Stanislav (2005): Cuentos y episodios del Persiles: de la isla bárbara a una apoteosis del amor bumano. Pontevedra: Mirabel Editorial. 